\title{
Social Media Addiction, Culture Code and Mediation Effect of Mindfulness: A Structural Equation Modelling Access
}

\author{
Anuradha, Thangaraja Arumugam, N.Akbar Jan, A.K. Subramani
}

\begin{abstract}
This study has been initiated with a view to understand the social media addiction and its influence on culture codes a mediation effect of mindfulness. The social media addiction would be a very common problem in the social and the organizational set up. The employees are getting distracted easily because of social media addiction. The organisations are taking much action to rectify this problem but end up with the talent lose because the employees are ready to quit the job when they are not allowed to use social media in the organisation. It has been an inevitable problem for the organisations so many techniques have been initiated in order to solve this problem. Many studies are concentrating on mindfulness which is a tool to remove the distractions and to be a focused employee in the organisation. The social media addiction many a times create a toxic culture among the employees. It needs a high attention to be cured. The employee relationship are highly under stake when they are social media addict. This study would attempt to understand the empirical evidence on this relationship by examining the association among addiction in social media and its effect on culture code and mediating role of mindfulness. This study also concentrates on the moderating role of gender on the proposed model.
\end{abstract}

Key words: Social Media addiction, Culture code, Mindfulness, SEM

\section{INTRODUCTION}

This study has been initiated with a view to understand social media addiction and its influence on culture codes as mediation effect of mindfulness. The social media addiction would be a very common problem in the social and the organizational set up. The employees are getting distracted easily because of social media addiction. The organisations are taking much action to rectify this problem but end up with the talent lose because the employees are ready to quit the job when they are not allowed to use social media in the organisation. It has been an inevitable problem for the organisations so many techniques have been initiated in order to solve this problem. Many studies are concentrating on mindfulness which is a tool to remove the distractions and to be a focused employee in the organisation. The social media addiction many a times create a toxic culture among the employees. It needs a high attention to be cured. The

Revised Manuscript Received on July 10, 2019.

Dr.Anuradha, Associate Professor, Institute of Management, Christ Deemed University, Bangalore, Karnadaka,India.

Dr. Thangaraja Arumugam, Associate Professor, SCMS School of Technology and Management, Cochin, Kerala,India.

Dr.N.Akbar Jan M.B.A., Ph.D., Faculty of HRM \& OB, IBS Hyderabad, The ICFAI Foundation for Higher Education (Declared as Deemed-to-be university u/s 3 of the UGC Act 1956), Hyderabad, Telangana, India.

Dr. A.K. Subramani, Associate Professor, Department of Management Studies, St. Peter's College of Engineering and Technology, Avadi, Chennai - 600054. Tamil Nadu, India. employee relationship are highly under stake when they are social media addict. This study would attempt to understand the empirical evidence on these relationship.

\section{RESEARCH OBJECTIVE}

To examine the association among addiction towards social media and its effect on culture code and mediating role of mindfulness. This study also concentrates on the moderating role of gender on the proposed model.

\section{REVIEW OF LITERATURE}

\section{Cultural Codes}

Interdependence amid levels and therefore the discernment of culture is habitually demonstrated via the usage of codes. The concept of 'Codes' maybe a confidential structure of behaviours, signs or words that are made to transfer messages that are circumstantially bound. Codes are often revealed at a perceptible level through rhetorical and plainspoken medium. Codes maybe the aftermath of the reactions of and exchange with varied cultural levels. This holds that what is noticed generally may not seem sensible to the outsider. Inventors and authors of codes constitute the insider group and codes are familiar only to them. These codes can be made use of as calligraphy by such groups for compactness or in allowing speedy communications. Codes may also be used to hide authentic messages and to conceal them from external forces. This applies not just to intelligence workers and masons but also for fulfilling research objectives as well.

Codes are made use of both voluntarily as well as involuntarily and they are hard to understand. Similar to a mysterious puzzle, it is indispensable to beguile the directive that will reveal the fundamental theme to make the crossword juxtaposed. Nonetheless the codes are split; we are left stumbling in a sphere of presumption, speculation and erroneous premise. This indicates our potential to impact metamorphosis via appraisal and other indistinguishable processes is consequentially diminished. We are in a peril of appearing on misinterpretation which indicates that our attempts to bring about differences are likely to be lead astray.

Codes subsist in gross cultures. Not just in cultures but in sub cultures as well. After all, they would materialize to be exceptionally supreme episode in a country like Europe (Both Eastern and Central) in the post-Communist epoch.

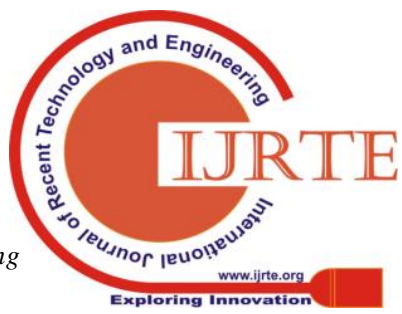




\section{SOCIAL MEDIA ADDICTION, CULTURE CODE AND MEDIATION EFFECT OF MINDFULNESS: A STRUCTURAL EQUATION MODELLING ACCESS}

Much before 1989, it could be proclaimed that the usage of codes was important to be conscious of the beliefs impermissible to the Party State to destabilize the encumbrance of amalgamated cultures and to operate in a system that promoted decreasing levels of certitude, hypothesis and self-defense. The disintegration of a wall did not bring a closure to these theories overnight. Furthermore, a different set of credence came into the picture inclusive of a bizarre and robust traction between 'a desire for artifacts Western' and reminiscences of 'renunciation' by the West half a century ago. Culturally or artistically, many of such nations plunged into a condition of flux and equivalently codes became hard to access and fathom. In addition, this was aggravated by an ancient correspondence of external interest in execution with command. Likewise, the idea of self-reflection had been furnished meaningless as personal and professional evolution was seldom self-sufficient. In a nutshell, many Europeans (Both from Eastern and Central Europe) underwent a profound ignorance wherein codes aided both to maintain the past order and to give articulation to the new.

In this frame of reference, Western donors and bureaucrats instigated the idea and enactment of assessment. These donors and bureaucrats specifically those with command over huge capital inclined to build evaluation by means of hitting deadlines and scanning resource-use. For instance, many schemes capitalized by the USAID and EU. In Sorokin locution, the primary 'homo-sapiens agents' to get into the 'alien' tradition brought a futuristic word 'evaluation' tied to similar terms such as regulated outcomes and 'control'. Furthermore, these impacts on the culture were vigorous since they were backed by an enormous reservoir which was deficient in Eastern and Central Europe back then. Many distant arbitrators came into this domain with varied insights of the objects of evaluation based on a hope in progress and edification. They also possessed competence but the competence of expertise not reservoir.

These entire artistes make use of codes in their nonamateur, civic and legislative positions. Comprehension of codes is difficult in resident culture. When a cluster of people belonging to differing nations and establishments with varied political and societal backgrounds are made to gather to do a work that is differently recognized, there is room for misunderstanding. This caters a predominant trial to the comportment of effective scrutinization and the occasion for transformation.

\section{SOCIAL MEDIA ADDICTION}

For investigating the sleep inducing imminent in online life, most at first to perceive need those people make routine with regards to such media. Kaplan and Haenlein (2010), it is characterized as 'a group of electronic demands that strengthen on the emotional and cutting edge substratum of Web 2.0 and which allows the development and exchange of substance that is client driven (p.61).

Social work discussions, at the end of the day, regularly known as web based life are examined high on close to home. The others variables of grouping are social nearness and wealth of media.

With investigating various models of online structures (For example, augmented reality models and web journals), one goes to the understanding that such connections are named medium on social substance productivity.

Social substance and media productivity might be characterized as 'the audile, visual and physical obstruction that can be accomplished that licenses to show up between talking members' thinking about the way that web based life grants inputs relating to correspondence

Expressed the quantity of people making utilizing of social work locales and relating web based life to social work destinations, we have embraced to focusing on this kind of innovation. In the year 2016, $78 \%$ of grown-ups had at absolute bottom 1 profile via web-based networking media (Statista.com, 2017) and dispensed a standard of 1.9667 hours once day by day via web-based networking media. In sharp differentiation to the start of the decade, normal divisions of grown-ups who utilize the Internet are on social stages. The fourth normal movement on the web is person to person communication.

Notwithstanding, the greater part of the client driven online networking send these destinations at first for social articles with basic divisions understanding that 'being in contact with existing relatives and companions is the central reason they utilize such locales' and half enlightening the equivalent concerning restoring bonds with old friends (Smith, 2011). This examination deciphers sticking to web based life as a subdivision of Youngs (200) Internet oppression on the grounds that the essential object of web based life seems, by all accounts, to be making and dragging out relations To acknowledge explicit components of social stage compulsion, Esgi (2016) actuated this work through the blooming of SMAT17 scale.

Online life sticking is a locution irregularly used to refer to somebody using lion's share of their time utilizing Instagram, Facebook, Twitter or some other web based life stages such that obstructs components of their normal life.

To college students who are millennial, social media sites are particularly important since it has been shown that a huge amount of time is spend with e-connected and the Internet is made use of by them for fulfilling social objects. One research indicated that students of colleges who were found to have problematic use of the Internet (As per Young's Internet Addiction Test) more frequently reported having issues in connection with the usage of Facebook Unexceptionally, administration of time was the chief concern that pupils underwent. Of late, Kircaburun (2016) discovered that addiction for social media was directly proportional to routine usage of Internet and amongst teens resulted in depression ultimately.

Another case seeking to govern about Generation Y who feels glued to social media disclosed that participants underwent flamboyance, forbearance, the intrapsychic factor of squabble and degeneration connected with their usage of social media (Cabral, 2011). In the opinion of Cabral (2011), interconnection of the factors of addiction with the users of social media shows, generation $\mathrm{Y}$ alphabetizes social media above other tasks and demands to using social media much more to attain satisfaction. Participants in this

Blue Eyes Intelligence Engineering 
study cognized state that there is a need to reduce the usage of such networks but discovered it was hard to do so. This detection identifies with themes visible in the study relating to Internet addiction coming to the conclusion that the generation $\mathrm{Y}$ is glued to social media.

With respect to diffusion of technology into each and adoption social media is indispensable to millennials. Nicholas Carr (2010) proposes that cyberspace technologies presently convoys the behavior of individuals and form their own views and as a matter of cause, contemporary society lives in a globe of interferences. These interferences are not coincidental; however, in fact they are present as a result of an individual's compulsion to regularly be in touch. According to Carr, these interruptions are altering the mannerism in which individuals process and transact data where cyberspace is partially held accountable to a huge deterioration in the skill to concentrate.

With the huge and periodic dependence for cyberspace technology, no obstruction is shown by individuals and what is left-they just don't prefer to. Disruptions have become the standard and concentration has become near to paradoxical (Carr, 2010; Mott, 2013). The automation aftermath is additionally presented in Roberts et al. (2014). Such researchers traversed the civic element of mobile device addictions wherein the usage of all type of gadgets, such as social media belvederes like Instagram and Pinterest may result in gluing onto social media.

Because of the opportunities that grant entry use the social media mesh on all the gadgets, where individuals are open to view or access the respective links at whenever they need and any number of times as per their respective choices. As per a research conducted by IDC which is an analytics firm, smartphone freaks "view their FB pages at a standard of fourteen times per day" (Subbaraman, 2013). The individuals today scan their FB accounts while shopping, exercising, and while they drive. Messages are delivered 24/7, it is impractical for many individuals to maintain a distance from the chosen social mesh for not more than just a little clock hours. Generation Y has been most addicted with regards to social media, which is todays fixed occupancy of the society. So the Y generation is not able to give up the addiction of social media. The researchers have used Martin et. al (2013) conceptual base for exploring the fact of the research, hence by takes into consideration the following questions to be answered :

RQ1: Demanded to refrain the social media, does the $Y$ Generation who constitute the student lot of colleges display addictive-like conducts? (For instance: close proximity with the phase of addiction)

Running Subject-line: Traversing social media gluing amongst the Y Generation.

RQ2: Is social media utilization by $\mathrm{Y}$ Generation in colleges representative of tardy phases of the consumption period based on their schedule or the number of times on social media podium (For instance: with close proximity to addiction or addiction episodes) ?

RQ3: Are the Generation Y college pupils likely to tread on the heels of flexible or dysfunctional consumption process not beyond the addiction phase? every element of the lives of $\mathrm{Y}$ generation, where the

\section{MINDFULNESS}

The theory of flow has connection with the theory of mindfulness which may be defined as a dynamic situation of apprehension wherein surveillance is concentrated on immediate setting and making schedules anew for conduct and is related with a consciousness of regulator and optimistic visceral (Kee and Wang, 2008; Moscardo, 2008). It is explained as a road to inevitable state for flow (Wright et al., 2006). The concept definition with regards to behavioural science (Langer, 1989), is a specimen where two-fold processing method is adopted, hence it is base for various concepts in the field of psychology (Evans and Curtis-Holmes, 2005; Smith and DeCoster, 2000). Processing done with binary model argue that humans generally retaliate in one of the two means to a circumstance-with trivial processing.

Another name for trivial processing is automatic processing and is concerned with notions regarding insensate patterns of thoughtful With respect to theory concerning mindfulness, trivial processing has linkages to mindlessness whereas in-depth processing has linkages to mindfulness. Binary processing concepts are customary in behavioural sciences and are made use of in various areas of societal perception inclusive of reckoning, discernment and choice creation (Evans, 2008). Example, two key models to elucidate eloquent exposé efficiency and change of attitudes, advancement plausibility type and trial and error methodical type are binary processing concepts.

The notion of binary processing is vital in optimistic psychology, wherein a significant distinction is made between indulgent contentment and welfare (Ryan and Deci, 2001). Former is an ephemeral condition related to minimal engagement with a condition, whereas the latter is a durable emotional state connected with in-depth refining and indistinguishable circumstances to those delineated for mindfulness, and probable contribution to all-embracing welfare and enhanced living standard. Mindfulness as a prudent situation to be revitalized in tourists since it has associations with a span of more optimistic outcomes. If this argument gains acceptance by us, then it is vital to comprehend the state estimated to mindfulness.

There is substantial convergence between the list and the attributes associated with optimistic examinations of tourists and consumer incidents which are itemized in the commencement of this division. Moscardo (2008) makes use of the convergences for proposing the usage of mindfulness with illustrative term in tourist encounters. She has confrontation, 2 group of elements embolden mindfulness. The initial ones are which snatch attention and those are inclusive of extreme inducements, creativity and revelation. So antecedents could visible with inevitable but insufficient to inspire mindfulness. Hence further elements above listed which can grab attention and motivate in-depth handling. Langer (1989) records a distinguishable contrast with regards to

Berlyne's (1960) task fundamental to curiosity. He argues that there are few cues that are environmental which are 


\section{SOCIAL MEDIA ADDICTION, CULTURE CODE AND MEDIATION EFFECT OF MINDFULNESS: A STRUCTURAL EQUATION MODELLING ACCESS}

probable to grab the concern to have a larger likelihood of which is straightly proportional to our instant endurance. But, it is also understand that they give out negligible threats, they are generally disregarded. A transparent linkage subsists here with the task on insentient patterns of thinking and involuntary processing (Bargh, 2006).

\section{METHODOLOGY}

This study includes the three latent variables namely Social media addiction, Mindfulness and culture code. These factors have got four items each which are taken as instrument through which the data collected. The instrument would contain 12 questions. E-format of the questionnaire was circulated among 183 respondents among which 100 responses were returned. This data were further taken for analysis through SPSS AMOS for model development. The teachers are the respondents of the research study those who are engaged in teaching for the student who are pursuing their higher education.

$\mathbf{H}_{1}$ : The social media addiction has an impact on culture code

$\mathbf{H}_{2:}$ The relationship between social media addiction and culture code is mediated by mindfulness

The above mentioned hypothesis are measured using structural equation modelling which tests the series of regression relationships. The latent variables consist of measured items which require scientific process of data validation and the factor reliability needs to be tested.

\section{RELIABILITY \& RESULT}

In the table.1, the items are checked with reliability through reliability statistics. The Cronbach Alpha value .744 denotes that the items are acceptable on reliability.

\section{Table1. Reliability Statistics}

\begin{tabular}{lll}
$\begin{array}{l}\text { Cronbach's } \\
\text { Alpha }\end{array}$ & $\begin{array}{l}\text { Cronbach's Alpha } \\
\text { Based on Standardized } \\
\text { Items }\end{array}$ & N of Items \\
.676 & .744 & 12 \\
\hline
\end{tabular}

\section{Table.2. Item Statistics}

Mean Std. Deviation N

\begin{tabular}{llll} 
Life style & 7.810000 & 1.3962793 & 100 \\
Language Usage & 3.672000 & .7005164 & 100 \\
Relationship & 5.365000 & 1.5304568 & 100 \\
Social Life & 5.442000 & 1.2084032 & 100 \\
Self realization & 4.010000 & 1.1269428 & 100 \\
Acceptance & 5.805000 & 1.3152850 & 100 \\
\hline
\end{tabular}

$\begin{array}{lll}5.123000 & 1.0723198 & 100 \\ 6.974000 & 1.5450553 & 100 \\ 6.043000 & .8197382 & 100 \\ 4.278000 & .9288398 & 100 \\ 3.886000 & .7344372 & 100 \\ 6.918000 & 1.1918393 & 100\end{array}$

Table.3.Scale Statistics

\begin{tabular}{llll}
\hline Mean & Variance & $\begin{array}{l}\text { Std. } \\
\text { Deviation }\end{array}$ & $\begin{array}{l}\mathrm{N} \\
\text { Items }\end{array}$ \\
65.326 & 42.838 & 6.545098 & 12 \\
\hline
\end{tabular}

The Table 2 provides mean value of the each items with the standard deviation. That shows the basic descriptive information of the data. Table. 2 gives the information about the variance in the data set. These would help understand the data nature and variance levels.

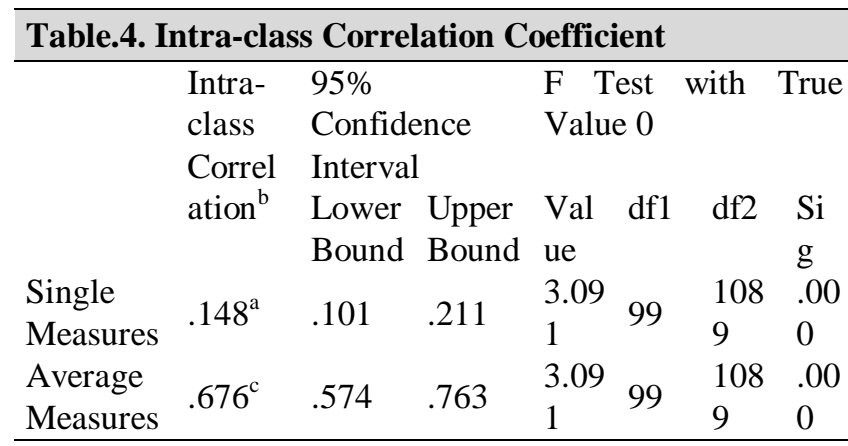

Two-way mixed effects model where people effects are random and measures effects are fixed.

a. The estimator is the same, whether the interaction effect is present or not.

b. Type $\mathrm{C}$ intraclass correlation coefficients using a consistency definition-the between-measure variance is excluded from the denominator variance.

c. This estimate is computed assuming the interaction effect is absent, because it is not estimable otherwise.

The above table reveals the recommended relative inter correlation and intra correlation statistics. The groups are better fit within and vary with the factor differences.

\section{STRUCTURAL MODEL}

A structural equation model has been developed with reliable latent exogenous and endogenous variables. The mediators' part is also measured with the model. The mediator may positively influence the association found among the variables of dependent and independent. 


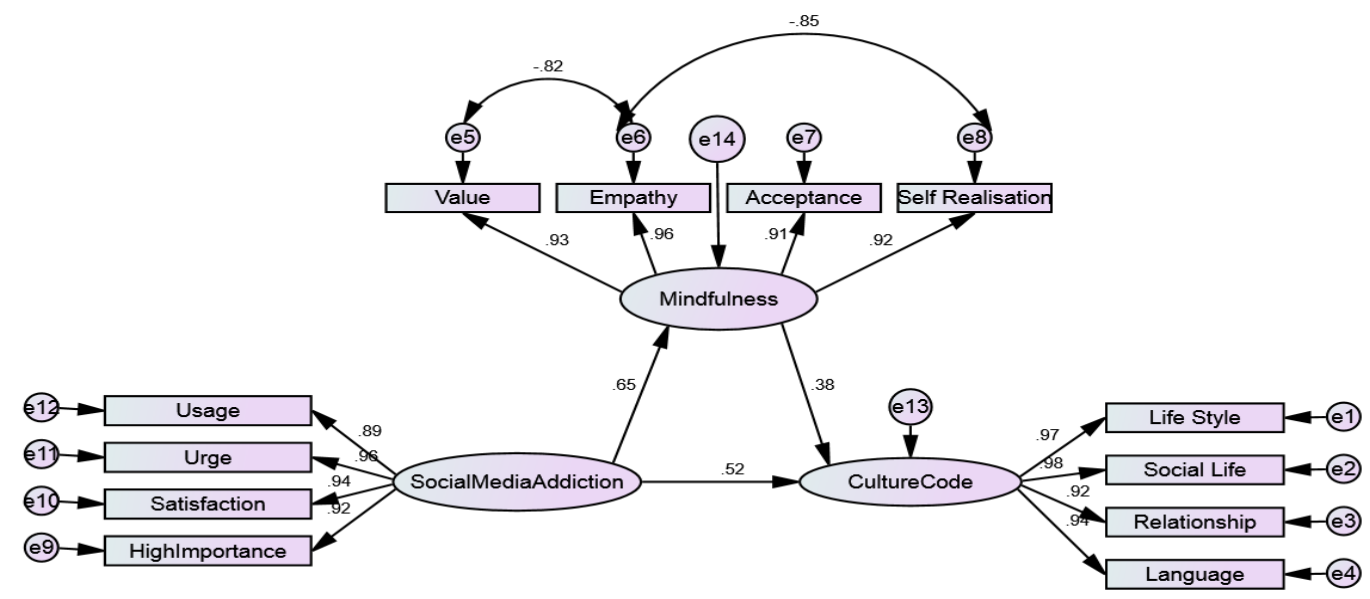

Model.1: Influence of addiction towards social media on culture code - Male

Model.2: Influence of addiction towards social media addiction on culture code - Female

\begin{tabular}{llllll}
\hline TABLE.5: CMIN - Model & NPAR & CMIN & DF & P & CMIN/DF \\
\hline Default model & 58 & 334.757 & 98 & .000 & 3.416 \\
Saturated model & 156 & .000 & 0 & & \\
Independence model & 24 & 12883.321 & 132 & .000 & 97.601 \\
\hline
\end{tabular}

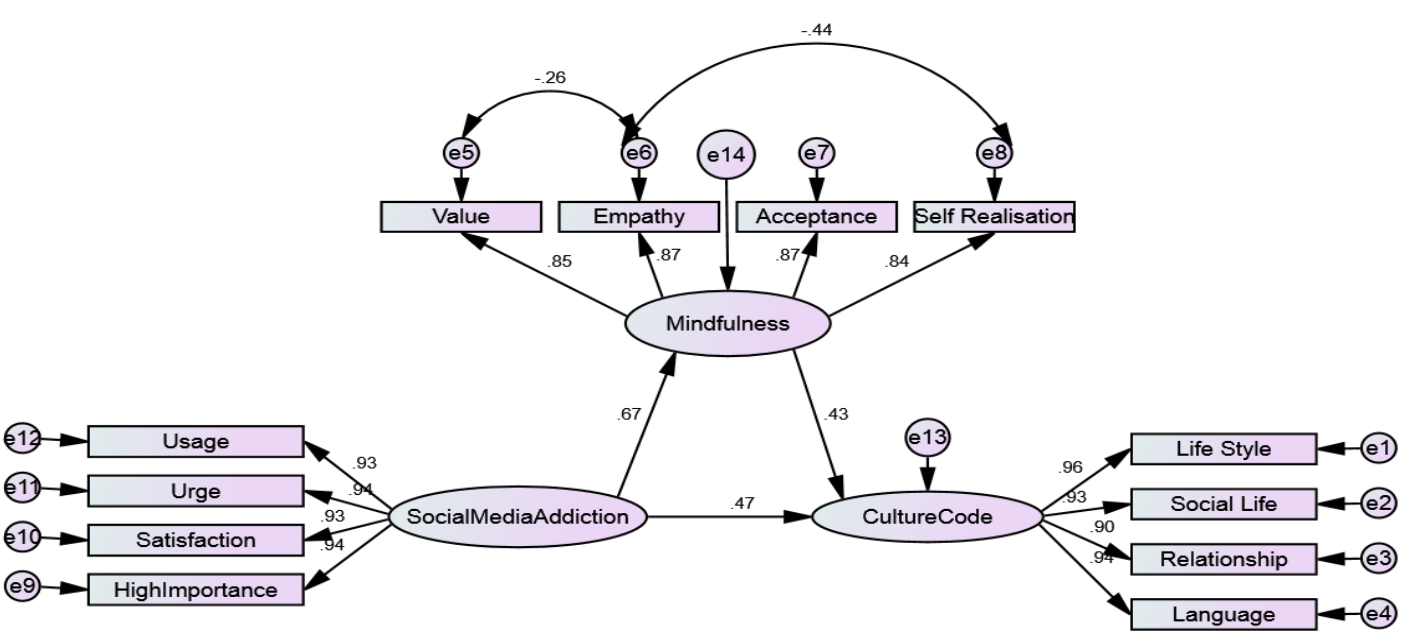

\begin{tabular}{llllllll}
\hline TABLE.6: RMR, GFI & RMR & GFI & AGFI & NFI & RFI & CFI & RMSEA \\
\hline Default model & .051 & .930 & .889 & .974 & .965 & .981 & .055 \\
Saturated model & .000 & 1.000 & & 1.000 & & 1.000 & \\
Independence model & 1.474 & .159 & .006 & .000 & .000 & .000 & .349 \\
\hline
\end{tabular}

The model shows a good fit with the CMIN/DF value (3.416) which needs to be less than the value of 5. The GFI $=.930, \mathrm{AGFI}=.889, \mathrm{NFI}=.974, \mathrm{RFI}=.965, \mathrm{CFI}=.981$ values are above the recommended levels. The goodness index are better fit with the model. On the other hand, the error level RMSEA value (0.55) is well below the recommended value. On the whole, the model gives a well fit so that it can be taken for the interpretation. The $\mathrm{H}_{1}$ shows the positive relationship and the full mediation has been identified. That shows a $\mathrm{H}_{2}$ is true. The relationship can be further analysed with the different sectors and different respondents.

\section{CONCLUSION}

The study has discovered an optimistic association among addiction towards social media and culture code, where the association was mediated by the mindfulness. The researcher has developed a theoretical design to examine the structural relationship among these factors and the mediator impact. This study infers a need of the addiction towards social media and its effect on the culture code. This can be further rectified when it is mediated by the mindfulness. The whole ideology can be further studied in the different sectors as this study focuses only on education sector.

\section{REFERENCES:}

1. Cabral, J. (2011), "Is generation Y addicted to social media?" The Elon Journal of Undergraduate Research in Communications, Vol. 2 No. 1, pp. 5-14.

2. Carr, N. (2010), The shallows: What the Internet is doing to our brains, W. W. Norton \& Company, New York, NY. 


\section{SOCIAL MEDIA ADDICTION, CULTURE CODE AND MEDIATION EFFECT OF MINDFULNESS: A STRUCTURAL EQUATION MODELLING ACCESS}

3. Esgi, N. (2016), "Development of social media addiction test (SMAT17)", Journal of Education and Training Studies, Vol. 4 No. 10, pp. 174-181.

4. Martin, I., (2013), "On the road to addiction: The Facilitative and preventive roles of marketing cues", Journal of Business Research, Vol. 66 No. 8, pp. 12191226.

5. Mott, N. (2013), "Evgeny morozov and Nicholas Carr on how we're all addicted to The Web", 12 March, available at: http://pandodaily.com/2013/03/12/evgeny- morozovand-Nicholas-Carr-on-how-were- all-addicted-to-theweb/ (accessed 19 March 2013).

6. Roberts, J., (2014), “The invisible addiction: Cellphone activities and addiction among male and female college students", Journal of Behavioral Addictions, Vol. 3 No. 4, pp. 254-265

7. Bargh, J.A. (2006), "What have we been priming all these years? On the development, mechanism, and ecology of nonconscious social behavior", European Journal of Social Psychology, Vol. 36 No. 2, pp. 147168.

8. Bargh, J.A. And Williams, E.L. (2006), "The automaticity of social life", Current Directions in Psychological Science, Vol. 15 No. 1, pp. 1-4.

9. Berlyne, D.E. (1960), Conflict, Arousal and Curiosity, McGraw Hill, New York, NY.

10. S.H. and Langer, E.J. (2006), "Mindfulness and selfacceptance", Journal of Rational-Emotive and Cognitive-Behavior Therapy, Vol. 24No. 1, pp. 29-43.

11. Houston, T. and Turner, P.K. (2007), "Mindfulness and communicative language teaching", Academic Exchange Quarterly, Vol. 11 No. 1, pp. 138-142.

12. Kee, Y.H. and Wang, C.K.J. (2008), "Relationships between mindfulness, flow dispositions and mental skills adoption: a cluster analytic approach", Psychology of Sport and Exercise, Vol. 9 No. 4, pp. 393-411.

13. Langer, E.J. (1989), Mindfulness, Addison-Wesley, Reading.

14. Langer, E.J. and Moldoveanu, M. (2000), "The construct of mindfulness", Journal of Social Issues, Vol. 56 No. 1, pp. 1-9.

15. McIntosh, A.J. (2004), “'Tourists' appreciation of maori culture in New Zealand", Tourism Management, Vol. 25 No. 1, pp. 1-15.

16. Moscardo, G. (1996), "Mindful visitors: creating sustainable links between heritage and tourism", Annals of Tourism Research, Vol. 23 No. 2, pp. 376387.

17. Moscardo, G. (2008), "Understanding tourist experience through mindfulness theory", in Kozak, M. and DeCrop, A. (Eds), Handbook of Tourist Behavior, Routledge, London, pp. 99-115.

18. Petty, R. and Cacioppo, J.T. (1986), "The Elaboration Likelihood Model of persuasion", in Berkowitz, L. (Ed.), Advances in Experimental Social Psychology, Academic Press, New York, NY, pp. 123-205.

19. Ritchhart, R. And Perkins, D.N. (2000), "Life in the mindful classroom: nurturing the disposition of mindfulness", Journal of Social Issues, Vol. 56 No. 1, pp. 27-47.

20. Ryan, R.M. And Deci, E.L. (2001), “On happiness and human potential: a review of research on hedonic and eudaimonic well-being", Annual Review of Psychology, Vol. 52 No. 1, pp. 141-166.

21. Seligman, M.E.P. and Csikszentmihalyi, M. (2000), "Positive psychology: an introduction", American Psychologist, Vol. 55 No. 1, pp. 5-14. 